\title{
Transcriptomic characterization and innovative molecular classification of clear cell renal cell carcinoma in the Chinese population
}

Qiang Zhao ${ }^{1 \dagger}$, Jia Xue ${ }^{2 \dagger}$, Baoan Hong ${ }^{1 \dagger} \oplus$, Wubin Qian², Tiezhu Liư ${ }^{3}$, Bin Fan $^{4}$, Jie Cai ${ }^{4}$, Yongpeng Ji ${ }^{1}$, Jia Liu $^{1}$,

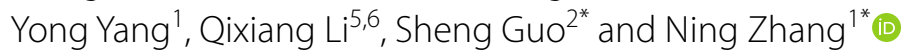

\begin{abstract}
Background: Large-scale initiatives like The Cancer Genome Atlas (TCGA) performed genomics studies on predominantly Caucasian kidney cancer. In this study, we aimed to investigate genomics of Chinese clear cell renal cell carcinoma (cCRCC).

Methods: We performed whole-transcriptomic sequencing on 55 tumor tissues and 11 matched normal tissues from Chinese ccRCC patients. We systematically analyzed the data from our cohort and comprehensively compared with the TCGA cCRCC cohort.

Results: It found that PBRM1 mutates with a frequency of $11 \%$ in our cohort, much lower than that in TCGA Caucasians (33\%). Besides, 31 gene fusions including 5 recurrent ones, that associated with apoptosis, tumor suppression and metastasis were identified. We classified our cohort into three classes by gene expression. Class 1 shows significantly elevated gene expression in the VEGF pathway, while Class 3 has comparably suppressed expression of this pathway. Class 2 is characterized by increased expression of extracellular matrix organization genes and is associated with high-grade tumors. Applying the classification to TCGA cCRCC patients revealed better distinction of tumor prognosis than reported classifications. Class 2 shows worst survival and Class 3 is a rare subtype ccRCC in the TCGA cohort. Furthermore, computational analysis on the immune microenvironment of ccRCC identified immune-active and tolerant tumors with significant increased macrophages and depleted CD4 positive T-cells, thus some patients may benefit from immunotherapies.
\end{abstract}

Conclusion: In summary, results presented in this study shed light into distinct genomic expression profiles in Chinese population, modified the stratification patterns by new molecular classification, and gave practical guidelines on clinical treatment of ccRCC patients.

Keywords: Transcriptomic characterization, Molecular classification, Clear cell renal cell carcinoma, TCGA, Immunophenotyping

*Correspondence: guosheng@crownbio.com; niru7429@126.com

${ }^{\dagger}$ Qiang Zhao, Jia Xue and Baoan Hong contributed equally to this work

${ }^{1}$ Key laboratory of Carcinogenesis and Translational Research (Ministry of Education/Beijing), Department of Urology, Peking University Cancer Hospital \& Institute, 52 Fucheng Road, Haidian District, Beijing 100142 , People's Republic of China

${ }^{2}$ Systems Biology, Crown Bioscience Inc., No. 218 Xinghu Street, Suzhou Industrial Park, Suzhou 215028, People's Republic of China

Full list of author information is available at the end of the article

\section{Background}

Kidney cancer, or renal cell carcinoma (RCC), accounts for about $2-3 \%$ of tumor malignancy in adults, and is one of the most lethal urological cancers [1]. Clear cell renal cell carcinoma (ccRCC) is its most common subtype (75-85\%). According to the data from the Chinese

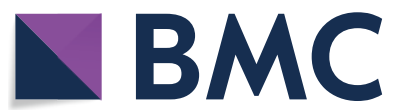

(c) The Author(s) 2020. This article is licensed under a Creative Commons Attribution 4.0 International License, which permits use, sharing, adaptation, distribution and reproduction in any medium or format, as long as you give appropriate credit to the original author(s) and the source, provide a link to the Creative Commons licence, and indicate if changes were made. The images or other third party material in this article are included in the article's Creative Commons licence, unless indicated otherwise in a credit line to the material. If material is not included in the article's Creative Commons licence and your intended use is not permitted by statutory regulation or exceeds the permitted use, you will need to obtain permission directly from the copyright holder. To view a copy of this licence, visit http://creativeco mmons.org/licenses/by/4.0/. The Creative Commons Public Domain Dedication waiver (http://creativecommons.org/publicdomain/ zero/1.0/) applies to the data made available in this article, unless otherwise stated in a credit line to the data. 
National Cancer Registry Center, over 67,000 new cases were diagnosed and 23,400 died in China in 2016, and these numbers are rapidly increasing each year. Due to the improvement of people's health consciousness and the upgrades of surgical techniques, 5-year survival rates of organ-confined disease can reach 70-90\% [2]. Patients with lymph node or systemic metastases suffer comparably worse with 5 - and 10-year survival rates of $5-30 \%$ and $0-5 \%$, respectively [3-5].

Besides clinical and histopathological features, RCC can be also characterized by underlying genomic variations and high immune infiltration [6]. Genomic characterizations of resource datasets on RCCs have been performed in the past few years, including clear cell renal cell carcinoma (ccRCC) [7-9], chromophobe renal cell carcinoma [10], papillary renal cell carcinoma [11] and renal medullary carcinoma [12]. One integrative taxonomy research has been performed to assemble three TCGA renal carcinoma subtypes [13].

Race and ethnicity cause inter-tumoral heterogeneity in cancers, ranging from disease incidence, morbidity, and mortality rates to treatment outcomes [14, 15]. Therefore, identification of population-specific molecular biomarkers is very important to this end. For example, Shi et al. utilized TCGA data to perform an integrative comparison between Caucasian and Asian Americans on gene expression patterns in breast cancers and found significant differences at gene and pathway levels [16]. But global genomic and transcriptomic similarities and dissimilarities between Asian and Caucasian for ccRCC remain largely unknown.

Cancers are increasingly recognized as collections of diverse not only genetic diseases, but also immune diseases. The heterogeneous tumor microenvironment (TME), including immune components, plays critical roles in tumor growth, progression and response to pharmaceutics, particularly immuno-oncology therapeutics. In recent years, immuno-phenotyping studies based on high-throughput assays on bulk tissue or single cell levels become more popular in oncology research $[9,17-20]$. Recently, two studies provided an immune atlas of ccRCC as inflammatory subtype of tumors by genomic analysis on bulk tumor level and by mass spectrometry single-cell level, respectively [17, 20]. It would be interesting to understand the underlying mechanisms for universal tumor-immune interactions in ccRCC.

To this end, we performed whole-transcriptome sequencing (WTS) on a cohort of 66 samples derived from 55 tumor tissues from Chinese ccRCC (CccRCC) patients and 11 of their matched normal tissues. We compared genetic variations and gene expression of CccRCCs with other large cohorts from TCGA and identified novel genomic features for ccRCCs in Chinese patients. Additionally, we uncovered new immunological characteristics for ccRCC progression and repression.

\section{Materials and methods \\ RNA isolation and WTS on CccRCC}

Freshly and surgically removed tumors and non-cancerous matched tissues (normals) were obtained from 55 patients diagnosed as ccRCC (These patients were enrolled from August 26th, 2016 to July 24th, 2017.) and frozen for storage. Total RNAs were extracted by RNeasy kit from (Qiagen) and the purity and integrity of the RNA samples (RIN $>7$ and $28 \mathrm{~S} / 18 \mathrm{~S}>1$ ) were determined by Agilent Bioanalyzer prior to sequencing. polyA + mRNA sequencing was performed by certified service providers at paired-end $150 \mathrm{bp}$ on Illumina HiSeq platform.

\section{External datasets retrieval and processing}

Level-3 TCGA RNA-seq data on kidney renal clear cell carcinoma or KIRC (533 tumor and 72 normal samples) were downloaded from the TCGA data portal (February 2015 release, https://tcga-data.nci.nih.gov/tcga/). RNAseq data generated by the Illumina HiSeq platform were used and processed by the RNAseqV2 pipeline, which used MapSplice [21] for read alignment and RSEM for quantification [22]. Clinical metadata of the three cancer types were obtained from the TCGA data portal (https:// portal.gdc.cancer.gov, November 2017) and converted to tab-delimited text tables.

\section{Bioinformatics analysis on RNA-seq data Gene mutation analysis}

Raw RNA-seq reads passed the FastQC tool (https:// www.bioinformatics.babraham.ac.uk/projects/fastqc/) default filters were aligned to the human genome assembly hg19. Somatic mutations on expressed genes were detected from aligned data for 55 tumor samples by the STAR mapping software [23] and the GATK variant discovery toolkit [24]. Several filtering steps were performed to exclude low-quality and germline mutations: (1) lowquality candidate events (i.e., the mutation events not tagged as PASS by GATK or with alternative allele depth smaller than 5 , and indel mutations in poly- $\mathrm{N}$ region or with alternative allele rate less than $20 \%$ ) were removed; (2) The mutation events that were observed in the 1000 Genome Project [25] and the 6500 Exome Project [26] with greater than $0.5 \%$ frequency were excluded; (3) the putative events should be within exonic regions and be protein-changing; (4) only mutations associated with cancer related genes (572 cancer consensus genes from COSMIC database (https://cancer.sanger.ac.uk/cosmi c) were retained [27]. The 11 matched normal samples were used as reference to further check the reliability 
of the detected somatic mutation. The remained putative mutations were used to infer driver mutations via a web tool-the Cancer Genome Interpreter (https://www. cancergenomeinterpreter.org/). To compare the overall mutation frequencies of driver mutation genes in the Chinese and Caucasian populations, Fisher's exact test was performed on each driver genes with $2 \times 2$ matrix of the sample counts with or without respective mutation in two datasets.

\section{Gene fusion detection}

Gene fusion information was detected by SOAPfuse [28] and Fusioncatcher [29] using mapped BAM files. Fusion events that are recurrent in more than one tumor sample were visualized as a circos plot [30].

\section{Gene expression data preprocessing and basic analysis}

Gene expression was estimated by the MMSEQ software [31] and raw gene counts were normalized by the RSEM software [22]. For the cross-dataset comparison of kidney cancer cohort for TCGA patients and CccRCC patients, "sva" package was utilized to estimate batch effect before pairwise Spearman correlation analysis on corresponding transcriptome [32]. "Rtsne" package was employed to ensure absence of batch effect between two datasets [33]. Differentially expressed (DE) genes and pathways between different clinical groups (Asian versus white, early pathologic stage versus late stage, lower histologic grade versus higher grade) were identified by using "Limma" and "GSVA" package with different cutoffs [34, 35]. Genes sets are derived from KEGG (https://www. genome.jp/kegg/), REACTOME (https://reactome.org/) and BIOCARTA (http://www.biocarta.com/) databases, which are integrated by MSigDB [36].

\section{RT-PCR and Sanger sequencing validation}

The genomic DNA of tumor and blood samples were isolated using DNeasy Blood and Tissue Kit (Qiagen Cat\#69506) following manufacturer's instruction. PCR amplification of amplified the mutation sites of PBRM1, and Sanger sequencing was used to verify the status of mutation sites. The PBRM1 primer sequences are provided in Additional file 1.

\section{Molecular classification of ccRCC}

The gene expression data matrix was z-score transformed and the maximum absolute deviation was calculated for each gene to select the top variable genes for clustering. The data were then transformed into a non-negative matrix and clustered using the "NMF" package [37]. First, we tested a series of gene numbers $(1500,2000$, $3000,4000,5000,6000$ and 7000). Rank estimates were calculated using 50 iterations of ranks $2-8$ with default settings. 3000 genes give best clustering with $k=3$. DE genes across NMF-derived subtypes were identified by comparing each class with other two and Top $300 \mathrm{DE}$ genes ranked by adjusted p-value among all comparisons were retained with the best recall of original NMF-based clustering using 3000 genes. Pathway enrichment analysis was performed on $300 \mathrm{DE}$ genes using REACTOME 2016 pathway database via Enrichr webtool (http://amp. pharm.mssm.edu/Enrichr/) [38, 39]. Pairwise Spearman correlation (COR) and distance matrix (1-COR) based on DE genes were determined for CccRCC samples $(n=55)$ combined with KIRC samples from TCGA $(n=533)$ as a complete cohort. Hierarchical clustering of distance matrix was performed to identify predicted classes. The classified KIRC samples were used for survival analysis.

\section{Transcriptional immuno-phenotyping analysis}

The mRNA expression of 66 immune markers proposed by TCGA Network [40] was plotted as a heatmap for all CccRCC samples (55 tumors and 11 normals) and TCGA KIRC samples separately, and hierarchical clustering was performed. Survival analysis of TCGA patients were then performed for immuno-stratified groups. The RSEMnormalized expression matrix of all genes for all CccRCC samples was utilized for deconvolution analysis by EPIC algorithm [41]. The signature scores of 6 human hematopoietic cell types were displayed as a stacked bar plot, where samples are ordered in the same immuno-stratified groups. Volcano plots showing $\log 10$ mean ratio and p-value between groups were drawn by comparing the inferred relative fractions from immune-active and tolerant tumors $(\mathrm{n}=51)$ versus immune-inactive tumors and normal samples $(\mathrm{n}=15)$.

\section{Results}

\section{Patient clinical information}

Transcriptome sequencing was performed on 55 tumor tissue samples from CccRCC patients, 11 of which with matched normal tissues. The clinical information, including age, gender, race, vital status, metastasis, pathologic stage and histologic grade, was summarized in comparison with the TCGA ccRCC cohort (Table 1). To note, our cohort is a slightly biased in early stages (Stage I: $50.1 \%$; Stage II: $10.7 \%$ ) and moderate grades (Grade 2: $43.0 \%$; Grade 3: 38.6\%) biased compared with the TCGA cohort and hitherto all patients are alive.

\section{Driver mutations and gene fusions}

To investigate population-specific genomic features, important driver mutations and recurrent gene fusions were identified in CccRCC tumors (Fig. 1). The median number of estimated somatic mutations for ccRCC patients is 54 per sample, at a comparable level to the 
Table 1 Clinical data summary of studied ccRCC datasets

\begin{tabular}{|c|c|c|c|c|}
\hline & CKC dataset & Percentage & TCGA dataset & Percentage \\
\hline Sample (matched normal) & $55(11)$ & & $533(72)$ & \\
\hline Average of age (range) & $58.3(25-80)$ & & $60.63(26-90)$ & \\
\hline \multicolumn{5}{|l|}{ Gender } \\
\hline Male & 41 & 74.5 & 345 & 64.7 \\
\hline Female & 14 & 25.5 & 188 & 35.3 \\
\hline \multicolumn{5}{|l|}{ Race } \\
\hline White & 0 & 0. & 462 & 86. \\
\hline Black & 0 & 0.0 & 56 & 10.5 \\
\hline Asian & 55 & 100.0 & 8 & 1.5 \\
\hline Not available & 0 & 0.0 & 7 & 1.3 \\
\hline \multicolumn{5}{|l|}{ Vital status } \\
\hline Alive & 55 & 100.0 & 358 & 67.2 \\
\hline Dead & 0 & 0.0 & 175 & 32.8 \\
\hline \multicolumn{5}{|l|}{ Metastasis } \\
\hline Mets- & 51 & 92.7 & 422 & 79.2 \\
\hline Mets+ & 4 & 7.3 & 109 & 20.5 \\
\hline Not available & 0 & 0.0 & 2 & 0.4 \\
\hline \multicolumn{5}{|l|}{ Pathologic stage } \\
\hline Stage I & 41 & 74.5 & 267 & 50.1 \\
\hline Stage II & 3 & 5.5 & 57 & 10.7 \\
\hline Stage III & 11 & 20.0 & 123 & 23.1 \\
\hline Stage IV & 0 & 0.0 & 83 & 15.6 \\
\hline Not available & 0 & 0.0 & 3 & 0.6 \\
\hline \multicolumn{5}{|l|}{ Histologic grade } \\
\hline Grade1 & 8 & 14.5 & 14 & 2.6 \\
\hline Grade2 & 29 & 52.7 & 229 & 43.0 \\
\hline Grade3 & 13 & 23.6 & 206 & 38.6 \\
\hline Grade4 & 4 & 7.3 & 76 & 14.3 \\
\hline Not available & 1 & 1.8 & 3 & 0.6 \\
\hline
\end{tabular}

TCGA cohort (KIRC: 44) (Fig. 1a). Due to lack of paired normal controls and the limitation of WTS technology, the mutation frequencies for the vast majority of important ccRCC variant genes, such as $V H L, B A P 1$ and SETD2, were shown in higher levels than in the TCGA cohort, except for PBRM1, a second most significantly mutated gene (SMG) $(33.7 \%$ in the Caucasian population) as previously described $[8,42]$, which was observed with only $14.5 \%$ mutation rate in Chinese patients (Additional file 2: Table S1a). RT-PCR and Sanger DNA sequencing confirmed that the true mutation rate of PBRM1 is $10.9 \%$. We further identified 191 putative driver mutations associated with 572 cancer consensus genes from the COSMIC database [27] (Additional file 2: Table S1b). The most frequently mutated driver genes are $V H L$ (78\%), BAP1 (19\%), NCOR2 (13\%) and SETD2 (11\%) in 53 samples with driver mutation (Fig. 1b). Fisher's exact test was then performed on each driver gene to investigate the overall mutation frequency difference between the Chinese and Caucasian populations. Significant difference $(p$-value $<0.05)$ in mutation frequencies between two populations was observed in 11 out of 84 driver genes, of which 3 were previously proposed SMGs in ccRCC [42], including $V H L$ ( $p$-value $=8.6 \mathrm{E}-4), P B R M 1$ $(p$-value $=8.4 \mathrm{E}-5)$ and $K D M 5 C \quad(p$-value $=3.8 \mathrm{E}-2)$ (Table 2). Further mRNA expression analysis indicated that PBRM1 mutation is associated with activation of the VEGF signaling pathways (Fig. 1c).

Thirty-one fusion events were detected in the CccRCC patients, five of which were observed in more than one sample (Fig. 1d). Functional analysis on the downstream related genes, e.g. PIR for the ACE2-PIR fusion, revealed their association with apoptosis, cancer suppression and metastasis, etc. (Additional file 3: Table S2). However, none of the fusion events was observed in TCGA patients [8]. 


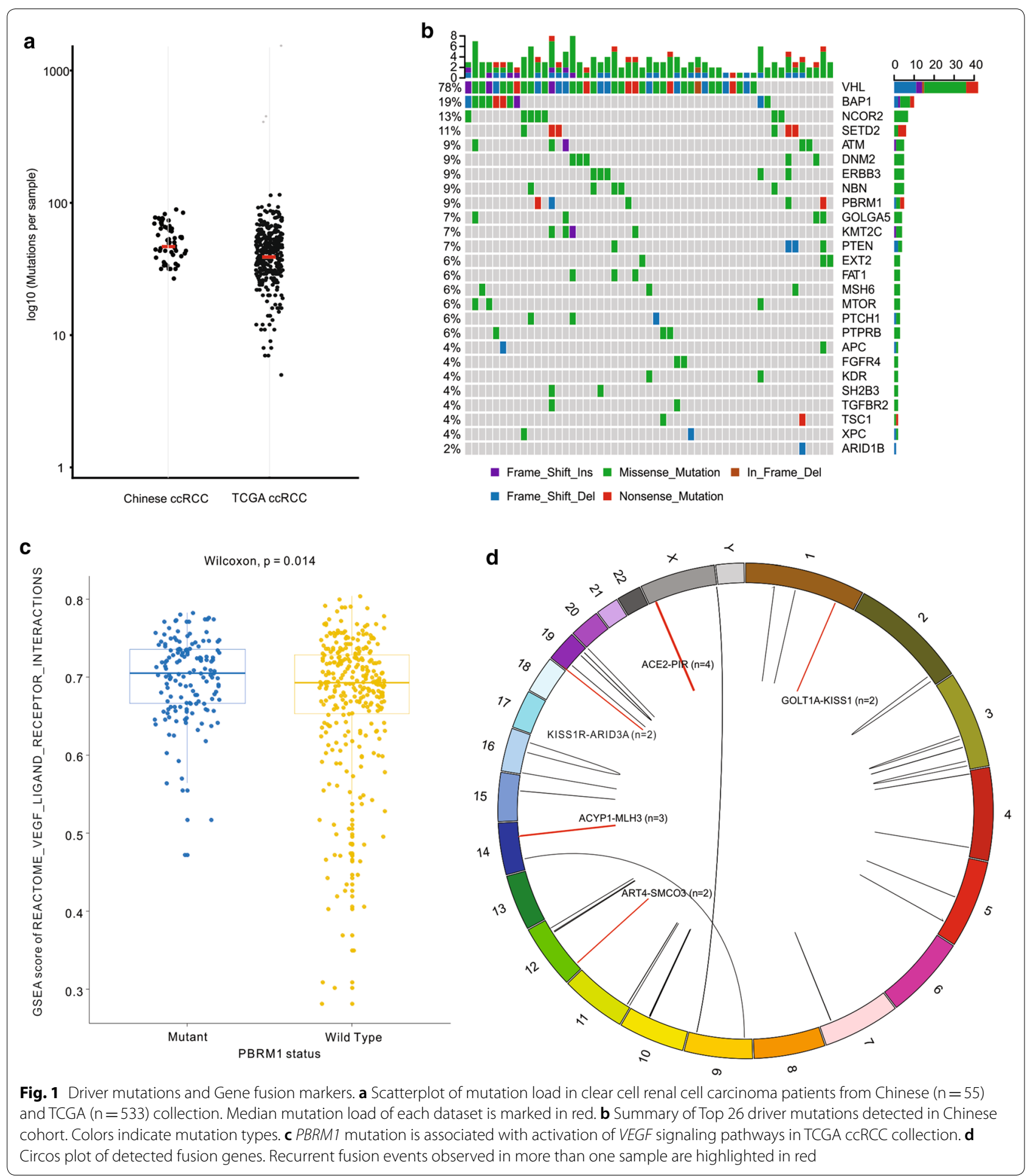

\section{Expression across populations and transcriptional} variations during tumor development

The gene expression profiles from both Chinese $(n=55)$ and TCGA $(n=533)$ ccRCC cohorts were integrated and compared for population specific variations. The
t-Distributed Stochastic Neighbor Embedding ( $t-S N E$ ) plot of the expression profiles from both datasets demonstrated a largely uniform distribution of Asian, white and black patients, suggesting low influence of race on transcriptomic level inter-tumoral heterogeneity (Fig. 2a). 
Table 2 The frequencies of driver mutation genes in CCCRCC and TCGA datasets

\begin{tabular}{|c|c|c|c|}
\hline Gene & $\begin{array}{l}\text { Frequency } \\
\text { in Chinese ccRCC } \\
(\%)\end{array}$ & $\begin{array}{l}\text { Frequency in TCGA } \\
\text { KIRC white (\%) }\end{array}$ & $\begin{array}{l}\text { p-value } \\
\text { (Fisher's } \\
\text { exact test) }\end{array}$ \\
\hline VHL & 76.4 & 52.8 & 0.000862049 \\
\hline BAP1 & 18.2 & 9 & 0.053248208 \\
\hline NCOR2 & 12.7 & 1.4 & 0.000127079 \\
\hline SETD2 & 10.9 & 11 & 1 \\
\hline PBRM1 & 9.1 & 33.7 & $8.38 \mathrm{E}-05$ \\
\hline ATM & 9.1 & 3.5 & 0.065990135 \\
\hline ERBB3 & 9.1 & 1.9 & 0.011804502 \\
\hline NBN & 9.1 & 0.4 & 0.000226619 \\
\hline DNM2 & 9.1 & 0.2 & $7.06 \mathrm{E}-05$ \\
\hline PTEN & 7.3 & 4.3 & 0.299167676 \\
\hline KMT2C & 7.3 & 3.8 & 0.269293981 \\
\hline GOLGA5 & 7.3 & 1.1 & 0.010440507 \\
\hline MTOR & 5.5 & 7.1 & 1 \\
\hline FAT1 & 5.5 & 3.5 & 0.449134307 \\
\hline PTCH1 & 5.5 & 2.1 & 0.131792795 \\
\hline MSH6 & 5.5 & 1.1 & 0.045880562 \\
\hline PTPRB & 5.5 & 0.9 & 0.031041033 \\
\hline EXT2 & 5.5 & 0.4 & 0.01040418 \\
\hline APC & 3.6 & 1.1 & 0.170756605 \\
\hline $\mathrm{KDR}$ & 3.6 & 1.1 & 0.170756605 \\
\hline$X P C$ & 3.6 & 1.1 & 0.170756605 \\
\hline TSC1 & 3.6 & 0.9 & 0.13083787 \\
\hline FGFR4 & 3.6 & 0.7 & 0.093628013 \\
\hline $\mathrm{SH} 2 \mathrm{~B} 3$ & 3.6 & 0.4 & 0.06033848 \\
\hline TGFBR2 & 3.6 & 0.4 & 0.06033848 \\
\hline FANCE & 1.8 & 4.3 & 0.711854112 \\
\hline PIK3CA & 1.8 & 4 & 0.70899921 \\
\hline TP53 & 1.8 & 3.3 & 1 \\
\hline POLE & 1.8 & 3.1 & 1 \\
\hline $\mathrm{CHD} 4$ & 1.8 & 2.6 & 1 \\
\hline SMARCA4 & 1.8 & 2.3 & 1 \\
\hline ATR & 1.8 & 2.1 & 1 \\
\hline CDK12 & 1.8 & 2.1 & 1 \\
\hline TET2 & 1.8 & 2.1 & 1 \\
\hline CHEK2 & 1.8 & 1.9 & 1 \\
\hline EGFR & 1.8 & 1.9 & 1 \\
\hline BLM & 1.8 & 1.6 & 0.604409035 \\
\hline FLT4 & 1.8 & 1.6 & 0.604409035 \\
\hline GNAS & 1.8 & 1.6 & 0.604409035 \\
\hline MYH11 & 1.8 & 1.6 & 0.604409035 \\
\hline TRRAP & 1.8 & 1.6 & 0.604409035 \\
\hline NCOR1 & 1.8 & 1.4 & 0.55540565 \\
\hline PIK3CB & 1.8 & 1.4 & 0.55540565 \\
\hline FBXW7 & 1.8 & 1.1 & 0.500455786 \\
\hline GATA2 & 1.8 & 1.1 & 0.500455786 \\
\hline KAT6B & 1.8 & 1.1 & 0.500455786 \\
\hline MLLT4 & 1.8 & 1.1 & 0.500455786 \\
\hline
\end{tabular}

Table 2 (continued)

\begin{tabular}{|c|c|c|c|}
\hline Gene & $\begin{array}{l}\text { Frequency } \\
\text { in Chinese ccRCC } \\
(\%)\end{array}$ & $\begin{array}{l}\text { Frequency in TCGA } \\
\text { KIRC white (\%) }\end{array}$ & $\begin{array}{l}\text { p-value } \\
\text { (Fisher's } \\
\text { exact test) }\end{array}$ \\
\hline TCF12 & 1.8 & 1.1 & 0.500455786 \\
\hline ERBB2 & 1.8 & 0.9 & 0.4388528 \\
\hline ARID1B & 1.8 & 0.9 & 0.4388528 \\
\hline ASXL1 & 1.8 & 0.9 & 0.4388528 \\
\hline $\mathrm{ClC}$ & 1.8 & 0.9 & 0.4388528 \\
\hline JAK3 & 1.8 & 0.9 & 0.4388528 \\
\hline MECOM & 1.8 & 0.9 & 0.4388528 \\
\hline NUP98 & 1.8 & 0.9 & 0.4388528 \\
\hline PER1 & 1.8 & 0.9 & 0.4388528 \\
\hline BARD1 & 1.8 & 0.7 & 0.369807843 \\
\hline DDR2 & 1.8 & 0.7 & 0.369807843 \\
\hline MET & 1.8 & 0.7 & 0.369807843 \\
\hline NDRG1 & 1.8 & 0.4 & 0.292440502 \\
\hline FANCG & 1.8 & 0.4 & 0.292440502 \\
\hline PLCG1 & 1.8 & 0.4 & 0.292440502 \\
\hline PMS2 & 1.8 & 0.4 & 0.292440502 \\
\hline PRF1 & 1.8 & 0.2 & 0.205768403 \\
\hline CEBPA & 1.8 & 0.2 & 0.205768403 \\
\hline MAP2K1 & 1.8 & 0.2 & 0.205768403 \\
\hline MYH9 & 1.8 & 0.2 & 0.205768403 \\
\hline PRDM1 & 1.8 & 0.2 & 0.205768403 \\
\hline TCF7L2 & 1.8 & 0.2 & 0.205768403 \\
\hline $\mathrm{FH}$ & 1.8 & 0 & 0.108695652 \\
\hline CDKN1B & 1.8 & 0 & 0.108695652 \\
\hline KLF6 & 1.8 & 0 & 0.108695652 \\
\hline PPM1D & 1.8 & 0 & 0.108695652 \\
\hline TRAF7 & 1.8 & 0 & 0.108695652 \\
\hline KDM5C & 0.0 & 6.9 & 0.037678184 \\
\hline ARID1A & 0.0 & 5.5 & 0.095406442 \\
\hline MALAT1 & 0.0 & 2.1 & 0.606792113 \\
\hline FGFR3 & 0.0 & 1.4 & 1 \\
\hline$A B L 2$ & 0.0 & 1.1 & 1 \\
\hline $\mathrm{BCL} 6$ & 0.0 & 1.1 & 1 \\
\hline CDK4 & 0.0 & 0.9 & 1 \\
\hline $\mathrm{CDH} 1$ & 0.0 & 0.7 & 1 \\
\hline PALB2 & 0.0 & 0.7 & 1 \\
\hline FANCF & 0.0 & 0.2 & 1 \\
\hline
\end{tabular}

Fisher's Exact test was performed for each gene by comparing the sample counts with mutant and wild type in two datasets

To examine the transcriptomic variation between patients with different tumor stages/grades, we used gene set variation analysis (GSVA) on the 55 tumor samples from Chinese ccRCC patients on 833 well-curated biological pathways. We observed a strong clustering of tumor samples by tumor grade, showing by 71 differentially expressed gene sets identified between grade groups (|Fold change $\mid>1.3$, p-value $<0.05$, Fig. $2 b$ ). A 
(See figure on next page.)

Fig. 2 Global overview of the transcriptomics of ccRCC patients. a The t-Distributed Stochastic Neighbor Embedding (t-SNE) plot of global mRNA expression for Chinese ( $C, n=55)$ and TCGA's $(T, n=533)$ cCRCC patients. Samples are colored by race. $\mathbf{b}$ Heatmap for gene set variation analysis (GSVA) on early (T1T2) and late (T3T4) clinical stages. Cutoffs used for GSVA were:|Fold Change|> 1.3 and Bonferroni \& Hochberg adjusted p-value $<0.05$

considerable number of pathways, especially pathways related to cell cycle, were significantly up-regulated in severe grade levels (Grade 3 and 4) than in mild level (Grade 1 and 2) (|Fold change $\mid>1.3$, p-value $<0.05$ ). Moreover, 91 differentially expressed gene sets are identified for stage groups ( $\mid$ Fold change $\mid>1.3$, p-value $<0.05$ ). The association between expression and tumor stages seems weak from clustering of pathways and genes (Additional file 4: Figure S1, Additional file 5: Figure S2).

\section{ccRCC classification by mRNA expression}

There have been several molecular classification schemes of ccRCC $[7,8,13]$. Most recently, ccRCC was classified into 3 subtypes using multilevel genomics data [13]. Such classifications, however, are sensitive to the number of genes used for statistical computation. Therefore, we used a robust iterative method to classify the Chinese ccRCC patients (see "Materials and methods"). The expression signatures obtained therefrom, if were more clinical-relevant than existing ones, should classify the TCGA ccRCC patients into groups with more distinct survival patterns, especially that we observed no pronounced population-specific transcriptomic profiling between the two patient cohorts.

Using our new method, the 55 CccRCC patients were clustered into 3 classes based on 3000 variable genes by unsupervised learning using the non-negative matrix factorization (NMF) algorithm (Additional file 6: Figure S3). Through iterations, top 300 differentially expressed genes were chosen as signature genes from the NMF-derived classes that, gave $94.5 \%$ agreement with that done by the original 3000-genes (Fig. 3a, Additional file 7: Figure S4). The most significantly enriched pathways for the 300 signature genes are extracellular matrix organization, hemostasis, and VEGF associated pathways, etc. (Additional file 8: Table S3).

The 300 signature genes were then used to classify TCGA ccRCC patients into 3 classes. Survival analysis of the three classes demonstrated significant difference in survival (log-rank test $p$-value $=1.55 \mathrm{E}-15)$, more so than that by the TCGA defined 3 subtypes, namely cc-e.1, cc-e. 2 and cc-e. 3 (log-rank test $p$-value $=8.94 \mathrm{E}-8$ ) [13]. Gene set enrichment analysis revealed that Class 1 tumors are characterized by significantly elevated VEGF pathway genes whereas those in Class 3 are comparably depleted (Kruskal-Wallis test $p$-value $=4.9 \mathrm{E}-16$, data not shown). Class 2 tumors, which possess increased expression of extracellular matrix organization genes (Kruskal-Wallis test $p$-value $=1 \mathrm{E}-15$, data not shown), were strongly associated with higher grade of tumors, and thus resulted in the worst overall survival (Fig. 3b). Comparison of median survival time for each patient group from our and TCGA classifications demonstrated better indication of survival groups in our classification (Fig. 3c). The median survival time of our Class 2 patients was only 1230 days, much shorter than the other two groups. In the TCGA classification, the cc-e.3 subtype had the worst survival, but its median survival was a much longer 1588 days. Cross comparison of the two classification schemes reveals that the majority ( 77 out of 88 ) of our Class 2 patients were in the TCGA cc-e. 3 subtype, which however had an additional 54 other patients. Further, Class 1 patients have overlap with all three TCGA subtypes and dominant in cc-e. 2 whereas Class 3 seems to be a rare novel subtype that has not been discovered in previous studies.

\section{Immuno-phenotyping}

To characterize tumor microenvironment in the CccRCC cohort, we first performed unsupervised hierarchical clustering of gene expression on 55 tumor and 11 matched normal samples by using a list of 66 immune markers proposed by the TCGA project [40]. Three distinct groups of tumors plus one group of normal samples were determined based on immuno-phenotyping. Seventeen tumor samples were with relatively high immune marker expression, and therefore, were defined as immune-active tumors; 4 tumor samples were clustered with normal tissues and had suppressed expression of the immune markers, hence, deemed as immuneinactive tumors; the remaining 34 tumor samples had intermediate levels of immune activity and were defined as immune-tolerant tumors (Fig. 4a). Such immune-phenotyping classification showed no observable correlation to the ccRCC classification determined in Fig. 3, suggesting immuno-phenotyping is independent of expressionbased ccRCC subtypes.

When such immune-phenotyping classification was applied to the TCGA ccRCC patients, we observed significantly longer survival in the immune-inactive patients than in the immune-active and immune-tolerant patients (log-rank test $p$-value $=1.8 \mathrm{E}-3) \quad$ (Fig. $4 \mathrm{~b})$. We further 

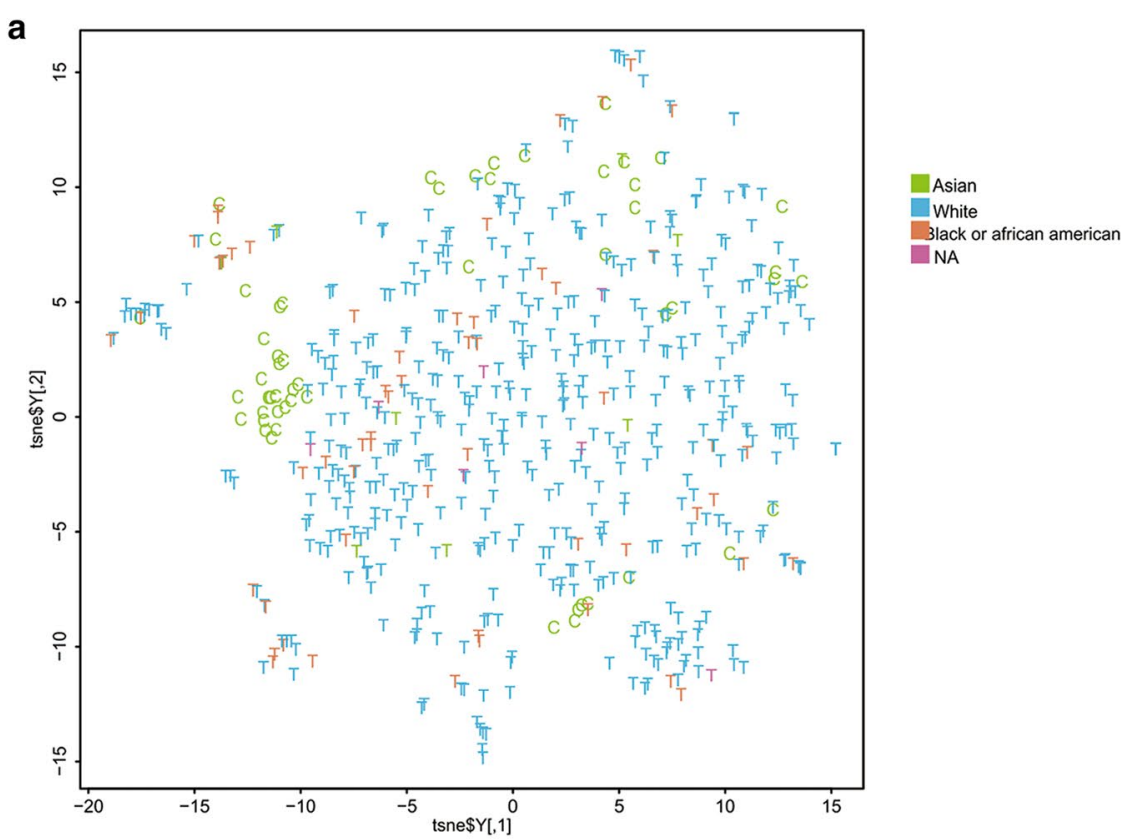

b

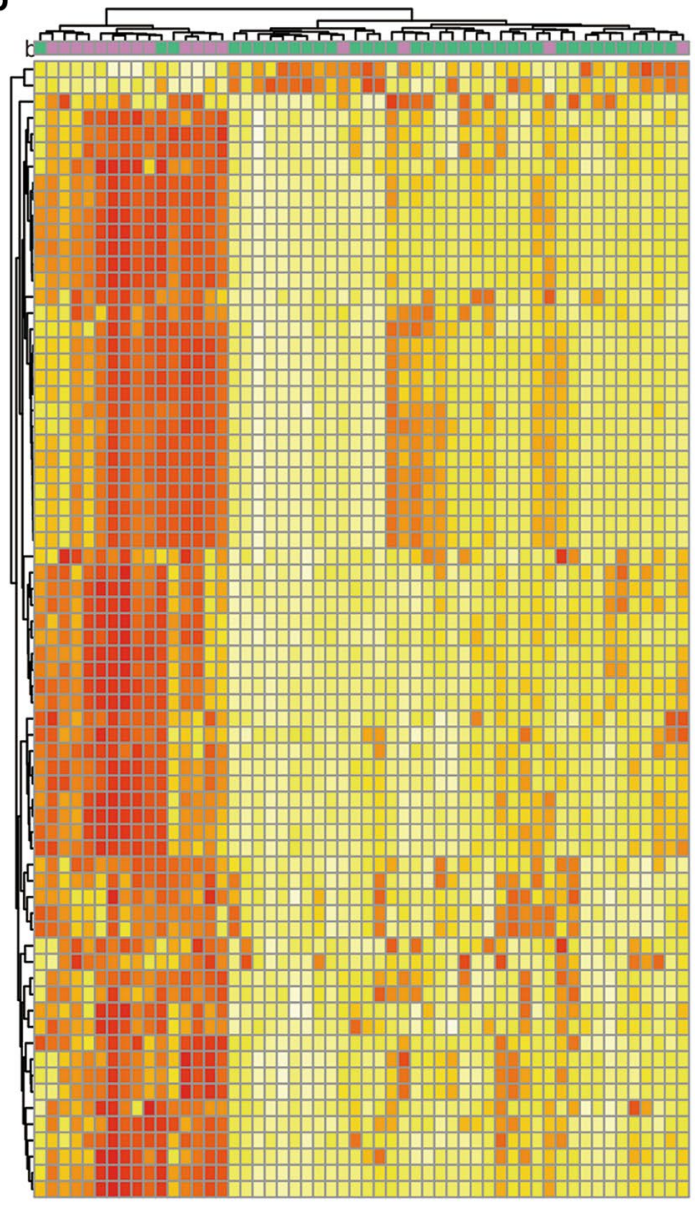

EACTOME-FORMATION ${ }^{-}$OF ATP BY CHEMIOSMOTIC COUPLING REACTOME-PREFOLDIN MEDIATED TRANSFER OF SUBSTRATE,TO CCT TRII BIOCARTA RANMS PATHWAY REACTOME M G1-TRANSITION

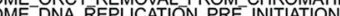
REACTOME-SYNTHESIS OF DNA REACOME-CEL-CYCLE CHECKPOINTS REACTOME-MICRORNA BDOGANESIS

作

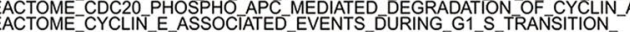

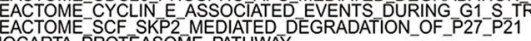

REACTOME AUTODEGRADATION_OF_CDH1_BY_CDH1_APC

REACTOME CDT1 ASSOCIATION WITH THE CDC6 ORC OOIGIN COMPLEX

TEACTOME-REGULATION OF ORNITHINE_DECARBOXYLASE

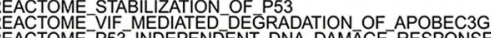

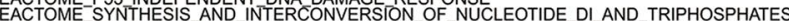

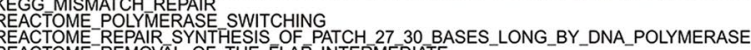
MEACTOME-REMOVAL_OF_THE_FLAP_NTERMEDIATE

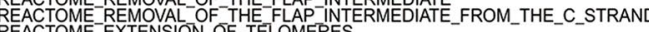

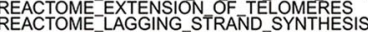

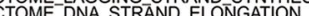

KEGG DNA-REPLICATION REACTOME_CDC6 ASSOCIATION WITH THE_ORC:ORIGIN_COMPLEX REACTOME-ERE-MEDIATED REGULATIOON OF DNA REPLICATION REACTOME-E2F-TRANSCRIPTIONAL_TARGETS_AT__G1_S

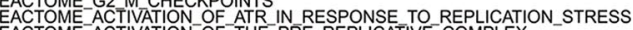

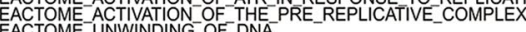

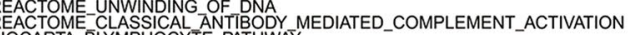
REACTOME CD28 DEPENDENT VAV1_PATHWAY

IOCATA-TCAPOPTOSIS PATHWAY

REACTOME-ACTIVATION OF CHAPERONES_BY_IRE1_ALPHA BIOCARTA_SALMONELLA PATHWA

OCARTA-P27 PATHAY

REACTOME EARLY PHASE OF HIV LIFE CYCLE

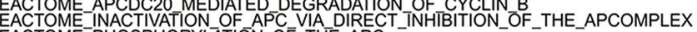
IOCARTA AKAP95 PATHWAY

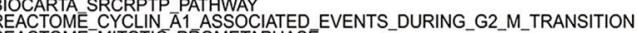
REACTOME-MITOTIC,PROMETAPHASE
REACTOME-MITOTICM M G PHASES
REACTOME-CELLCYCLEMITOTIC 
classified TCGA ccRCC patients into 9 groups using both the expression-based and immuno-phenotyping classifications, and observed more distinct survival difference than either single classification (log-rank test $p$-value $=2.40 \mathrm{E}-14)$, and as expected, we observed that the immune-active and immune-tolerant patients in Class 2 had the worst survival (Fig. 4c).

To identify infiltrating immune components within these samples, we performed tumor-immune interaction estimation analysis on CccRCC tumor and normal samples by the EPIC algorithm [41] (Additional file 9: Figure S5a). The composition of infiltrating immune repertoire presented remarkable heterogeneity across CccRCC patients. By comparing the immune and stroma contents in immune-active and tolerant tumors with immune-inactive tumors and normal tissues, macrophages, endothelial cells and cancer associated fibroblasts (CAFs) were observed as significantly elevated cell types in the former group (Additional file 9: Figure S5b) whereas $C D 4$ positive $\mathrm{T}$ cells are depleted, indicating macrophages and inflammation plays important role in these tumors. Moreover, as the tumor mutational burden (TMB) is reported to be associated with immunotherapy in diverse cancers [43, 44], we roughly estimated TMB (as eTMB) by the number of somatic mutations for the 11 paired samples using the RNA-seq data (Additional file 10: Table S4a). From this small sample size estimation, we did not observe clear correlation between the computed eTMB and the immunophenotyping we identified in Fig. 4a, however, we could see some evidence of the correlation between TMB and CD8+ T cells and macrophages contents in TME (Additional file 10: Table S4b).

\section{Discussion}

This study aimed to understand the transcriptomics of Chinese ccRCC from the RNA-seq data. We first investigated gene mutations. Due to lack of sufficient matched tumor adjacent normal tissue samples and comparatively lower sensitivity of WTS-based detection, heuristic methods were used to detect and infer somatic mutations. We observed slight difference in occurrence and frequency for the previously found significantly mutated genes in TCGA ccRCC cohorts [42], except for PBRM1, whose mutation frequency in our cohort is much lower than in Caucasians. The RNA sequencing quality and depth at PBRM1 coding region were sufficient
(Additional file 11: Table S5). Inference of gene mutation from transcriptomic data may be affected by several factors including DNA mutations that impact RNA transcript stability (e.g. through nonsense mediated decay), RNA editing that plays a role in cancer development [45], low expression of RNA that leads to undetected mutations. To evaluate whether DNA mutations affect RNA transcript stability and subsequently mRNA expression, we compared PBRM1 expression between missense mutation, truncating mutation (some leading to nonsense mediated decay), and wild type in the TCGA clear cell renal carcinoma cohort (Additional file 12: Figure S6a). Indeed, we observed a lower PBRM1 expression in patients with truncating mutations. However, all patients have significant PBRM1 expression. Similarly, PBRM1 has quite measurable expression levels in the CccRCC cohort, and no significant difference is detected between tumor and normal samples (Additional file 12: Figure S6b). Therefore, it is unlikely that DNA mutations cause low PBRM1 mutation frequency in the CccRCC cohort. From Additional file 12: Figure S6a we also observed that about $80 \%$ of $P B R M 1$ mutations are truncating mutations. In the 8 validated $P B R M 1$ mutations in the Chinese cohort, 6 or $75 \%$ are truncation mutations (Additional file 2: Table S1b). We therefore conclude that the low PBRM1 mutation frequency in the CccRCC cohort is unlikely artifact.

PBRM1 was previously reported to be associated with slightly worse stage and grade tumors by immunohistochemistry [46], however, the domination of early stage (78.4\%) and low grade (66.1\%) samples in our dataset might bias the observation. Nevertheless, remarkably low frequency of PBRM1 mutation frequency (11\%) was also reported in Polish population with a samples size of 83 patients and no bias in early stage and low grade [47]. PBRM1 is involved in the regulation of genes of metabolic pathways that is known to be essential for driving ccRCC, including the hypoxia response related $P I 3 K$ signaling pathway [48], high percentage of wild type $P B R M 1$ could be one reason why better treatment outcome of PI3K inhibitor was observed in the Chinese population (data not shown). PBRM1 mutation status could also be related to immunotherapy efficacy. A recent study reported that ccRCC patients with PBRM1 mutational inactivation benefits more from PD-1 inhibitors than those with wild type PBRM1 [49].

\footnotetext{
(See figure on next page.)

Fig. 3 Clear cell renal cell carcinoma classification. a Chinese and TCGA cCRCC patients $(n=588)$ are classified into three subtypes based on NMF-clustering derived 300 genes. b Survival analysis on three identified classes of TCGA ccRCC patients revealed significant difference. The log rank test $p$-value across groups is 1.55E-15. c Comparison of CccRCC-defined ccRCC classification $(n=533$ and $n=488)$ with TCGA's classification $(n=488)$ by stratification of survival curves. $\mathbf{d}$ Overlap of samples classified in CccRCC and TCGA's classification. The largest intersection for Class 1-3 is highlighted in red
} 


\section{a}

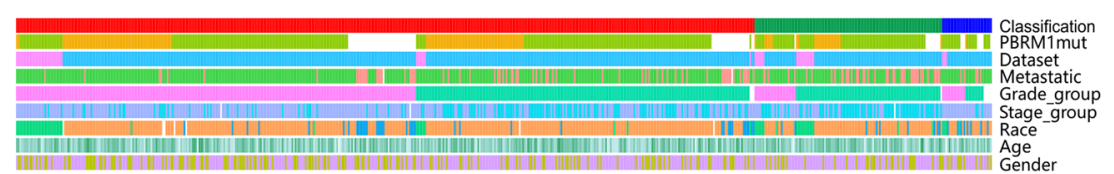

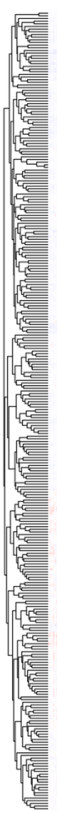

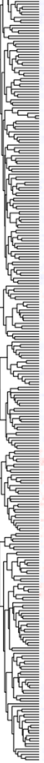

20
10

$-10$

$-20$

Classification

Class 2
Class 2
Class 3

PBRM1mut

Mut
WT

Dataset
CCcRCC

$\mathrm{CCCRCC}$
$\mathrm{TCGA}$

Metastatic

$\mathrm{N}$

Grade

G3G4

Stage
T112
T3T4

Race

Black or african american

Age
90

30

Gender
F
M

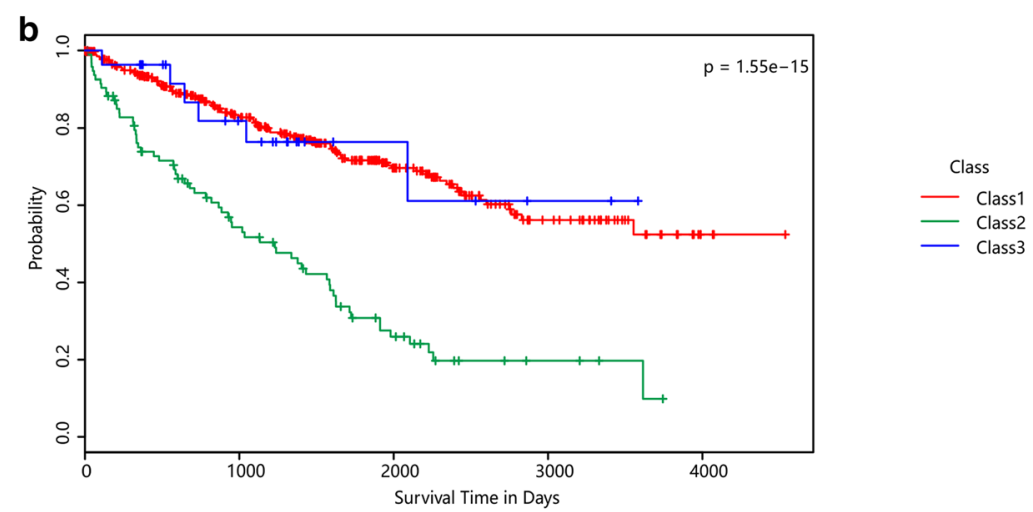

C

\begin{tabular}{|c|c|c|c|c|c|}
\hline $\begin{array}{c}\text { CccRCC } \\
\text { classification }\end{array}$ & \# of samples & \# of events & $\begin{array}{c}\text { Median } \\
\text { survival time }\end{array}$ & $0.95 \mathrm{LCL}$ & $0.95 \mathrm{UCL}$ \\
\hline Class 1 & 410 & 105 & NA & 2830 & NA \\
\hline Class2 & 96 & 64 & 1230 & 866 & 1610 \\
\hline Class3 & 27 & 6 & NA & 2090 & NA \\
\hline $\begin{array}{c}\text { CccRCC } \\
\text { classification }\end{array}$ & $\#$ of samples & \# of events & $\begin{array}{c}\text { Median } \\
\text { survival time }\end{array}$ & $0.95 \mathrm{LCL}$ & $0.95 \mathrm{UCL}$ \\
\hline Class 1 & 399 & 103 & NA & 2764 & NA \\
\hline Class2 & 88 & 61 & 1133 & 866 & 1610 \\
\hline Class 3 & 1 & 0 & NA & NA & NA \\
\hline $\begin{array}{c}\text { TCGA 2016 } \\
\text { CellReports } \\
\text { ccRCC classification }\end{array}$ & $\#$ of samples & \# of events & $\begin{array}{l}\text { Median } \\
\text { survival time }\end{array}$ & $0.95 \mathrm{LCL}$ & $0.95 \mathrm{UCL}$ \\
\hline cc-e.1 & 103 & 37 & 2564 & 1986 & NA \\
\hline cc-e. 2 & 254 & 56 & NA & 3554 & NA \\
\hline cc-e.3 & 131 & 71 & 1588 & 1191 & 1980 \\
\hline
\end{tabular}

d

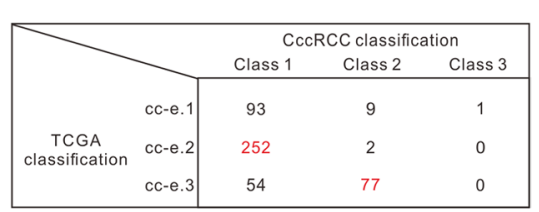




\section{a}
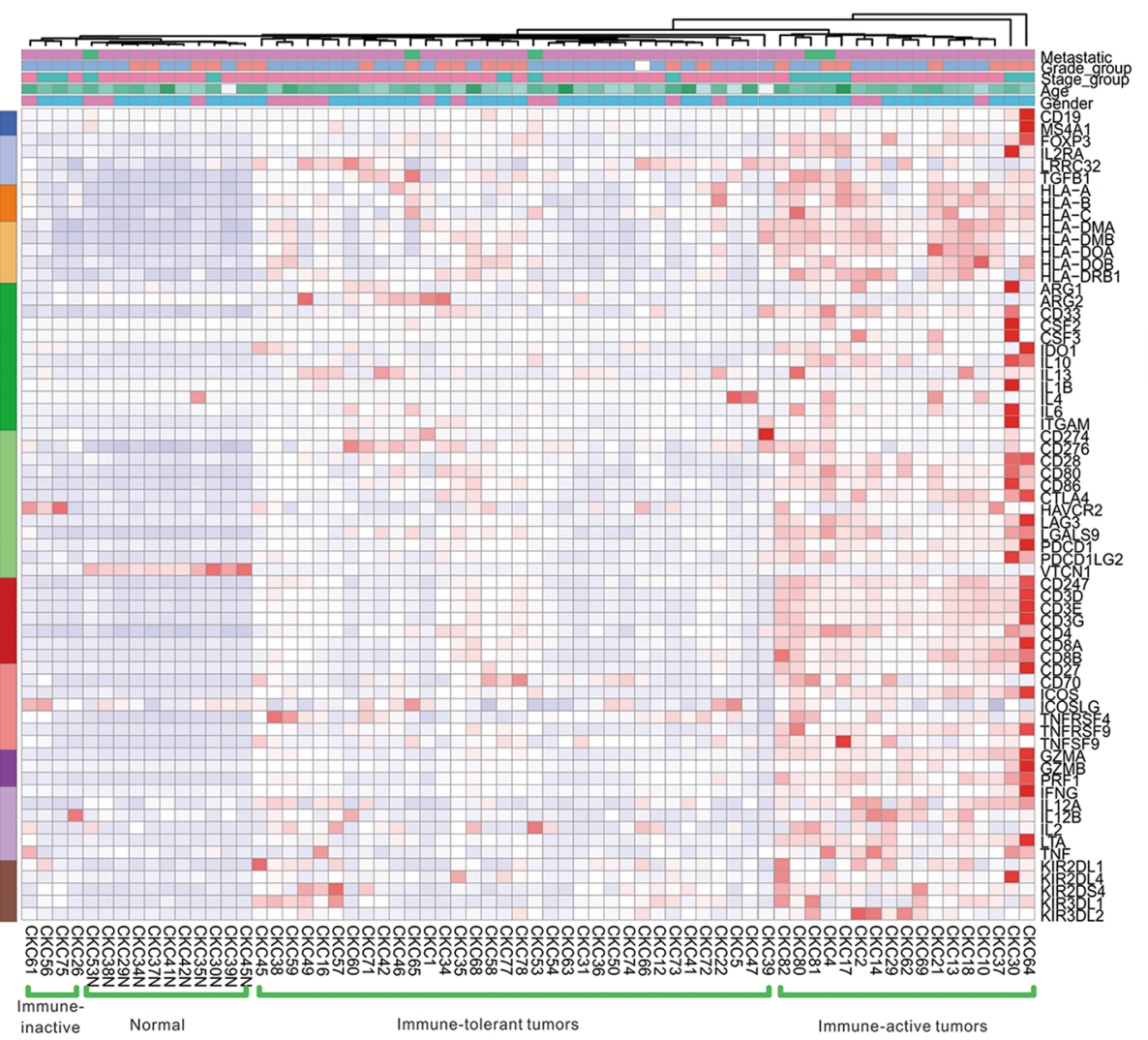

Metas

Grade group

$\mathrm{G} 1 \mathrm{G} 2$
$\mathrm{G} \mathrm{G} 4$

Stage group

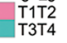

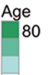

30

Gender

5

0
-5

Markers
B cell

Treg

MHCI

MDSC

Checkpoint

T cell co-receptor

Activator

Effector protein

NK receptor

b

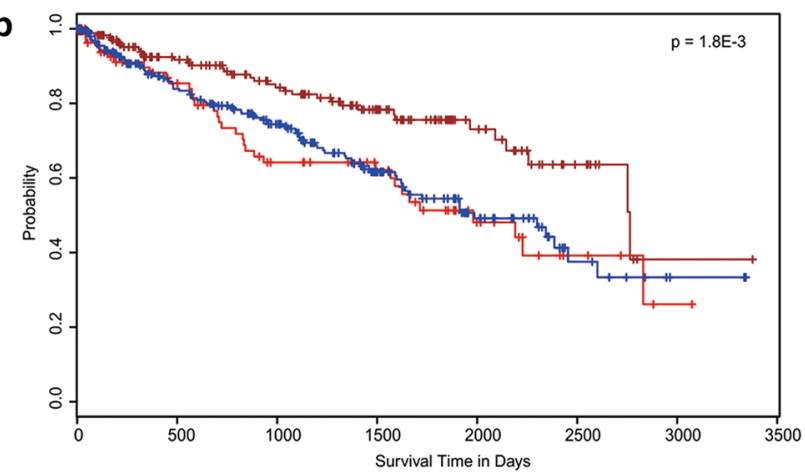

Immunophenotyping
三 active
吕erant
inacactive

C

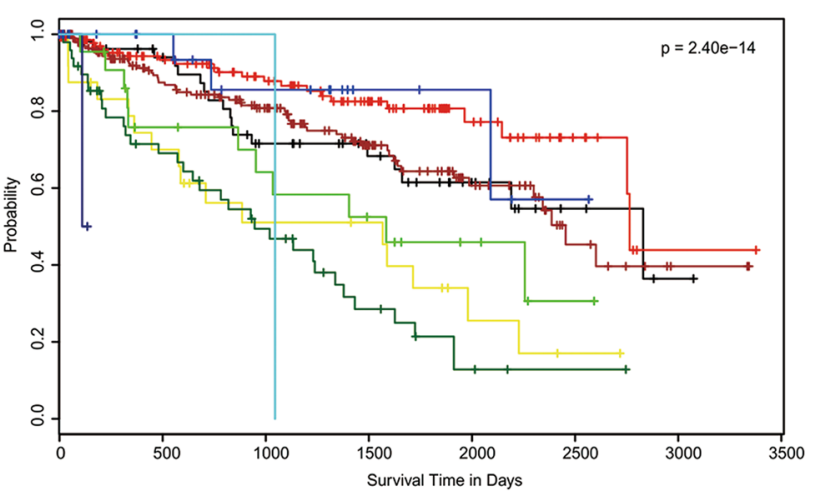

Group combination

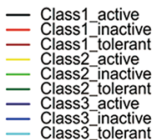


(See figure on previous page.)

Fig. 4 Transcriptional Characterization of Immune Microenvironment of ccRCC. a Unsupervised hierarchical clustering of immune gene expression within CcCRCC patients (including tumor and normal samples, $n=66$ ). A signature of 66 immune related cell markers proposed by TCGA was used for clustering. $\mathbf{b}$ Survival analysis on TCGA ccRCC patients $(n=533)$ grouped by three identified immuno-phenotypes (immune-active, tolerant and inactive) revealed significant difference. The log-rank test $p$-value across groups is 1.8E-3. c Survival analysis on combination of classification. TCGA patients were grouped by combination of molecular classification from Fig. 3 (Class 1-3) and immuno-phenotyping (immune-active, tolerant and inactive). The log rank test $p$-value across groups is $2.40 \mathrm{E}-14$

We used expression data to classify ccRCC patients. Large-scale molecular diagnosis of cancer plays more and more important role in precision medicine [50,51]. Unsupervised clustering algorithms were usually used for classifying a cancer into subtypes. Such classifications are sensitive to various parameters used in the numeric operations, such as number of genes used. From a practical and clinical point of view, a good classification should generate subtypes with distinct clinical prognosis and unique pathway activations that can be treated accordingly. As the Chinese cohort in this study lacks clinical survival information (all patients involved in this study were fortunately all alive at the time of this report), we used the TCGA ccRCC data to test our classification. The most recent multi-platform taxonomy of RCC from TCGA resulted in stratified survival groups (log rank $p$-value $<1 \mathrm{E}-7)$ with three ccRCC related subtypes [51], which is in favor of their previous mRNA-based clustering in 2013 [8]. Our classification further improved the stratification in overall survival. In addition to favorable distinction of survival curves, we could better correlate our classification with tumor grade levels. Although Class 1 and Class 3 tumors resulted in similar survival behavior, significant expression difference in ccRCC-driven pathways such as VEGF signaling pathway indicate that these two subtypes might be caused or impacted by distinct molecular mechanism, and should be treated differently. Using our classification, we already put more emphasis on the follow-up care of the Class 2 patients, results of which will be reported in the future.

Finally, we investigated the immuno-phenotyping of CccRCC patients. A previous study applied mass cytometry for multi-dimensional single-cell analysis on ccRCC but focused only on tumor associated macrophages and $\mathrm{T}$ cells due to limited number of channels [17]. Dissecting molecular signals of immune cells from TME in bulk tumor WTS by deconvolution analysis is a more convenient and cost-effective way than experimental technologies albeit resulting in insufficient resolution and precision [52-54]. Recent immunogenomic analysis on TCGA dataset identified that ccRCC is dominant of inflammatory subtype [55], which is also confirmed in CccRCC patients by our computing of cell fractions of TME cell types using the EPIC algorithm [41]. We further demonstrated that macrophages play more role in "immune-active" and "immune-tolerant" ccRCCs by comparing across samples. Further understanding of the tumor-associated macrophages might be helpful to perform respective cell-mediated immunotherapy for these patients in the future. The combination of immunephenotyping and mRNA expression data for classifying ccRCC into 9 subtypes also gave better resolution on patient prognosis.

\section{Conclusion}

In summary, results presented in this study shed light into the prognostic difference across populations, and gave practical guidelines on clinical treatment of ccRCC patients.

\section{Supplementary information}

Supplementary information accompanies this paper at https://doi. prg/10.1186/s12935-020-01552-w.

Additional file 1. PBRM1 primer sequences used in RT-PCR and Sanger sequencing.

Additional file 2: Table S1. a: this table gives the detailed information for detected driver mutation in CcCRCC dataset. b: this table gives RT-PCR and Sanger sequencing validation of computational predicted PBRM1 somatic mutations from RNA-Seq technology. Confirmed somatic mutation are highlighted in yellow.

Additional file 3: Table S2. This table contains detailed information on detected gene fusion events discovered in 55 CccRCC tumor samples.

Additional file 4: Figure S1. Identification of pathway variation on different clinical groups. Heatmap for gene set variation analysis (GSVA) on early (T1T2) and late (T3T4) clinical stages. Cutoffs used for GSVA were: unadjusted $p$-value $<0.01$.

Additional file 5: Figure S2.Principle Component Analysis (PCA) on whole transcriptomes of 55 CcCRCC reveals weak association between tumor stage gene expression. a: PCA plot colored by grade groups; b: PCA plot colored by stage groups.

Additional file 6: Figure S3. Non-negative matrix factorization (NMF) clustering for CcCRCC. Heatmap for NMF classification within all CcCRCC samples for ranks 2-8 using 50 iterations.

Additional file 7: Figure S4.Identification of gene expression based cCRCC classification. a. Heatmap for alignment of NMF based CcCRCC classification to TCGA samples $(n=533)$ using 300 differentially expressed genes. $\mathbf{b}$. Overlap of final predicted classes with original NMF-derived classes on CccRCC patients ( $n=55)$.

Additional file 8: Table S3. a: this table gives the top 300 differentially expressed genes between three classes defined by NMF clustering algorithm. b: this table contains top 20 significantly enriched Reactome pathways in the top 300 differentially expressed genes between three 
classes defined by NMF clustering algorithm. c: this table summarizes the molecular classification of cCRCC samples in both Chinese and TCGA datasets.

Additional file 9: Figure S5. Identification of infiltrating immune cells in CcCRCC. a. Relative fractions of tumor associated immune and stromal cells within all CccRCC samples. Samples were ordered as in the same clustering in Fig. 4. CAFs: cancer associated fibroblasts. b. Log10-transformed mean ratio ( $x$-axis) versus $p$-value from student $t$-test for immuneactive and tolerant tumors versus immune-inactive tumor and normal samples are shown. Only cell types with significant variance $(p<0.05)$ are labeled and highlighted in red (elevated) or blue (depleted).

Additional file 10: Table S4. a: this table gives the estimated tumor mutational burden (eTMB, the number of somatic mutations) and cell fractions from bulk expression matrix for 11 paired CccRCC samples. $\mathbf{b}$ this table summarizes the pairwise correlation between eTMB and the corresponding cell fraction values from $\mathbf{a}$.

Additional file 11: Table S5. a: this table provides whole transcriptome sequencing quality of 65 test samples in Chinese ccRCC dataset; b: this table summarizes the average depth of reads mapped to PBRM1 CDS region for Chinese cCRCC samples.

Additional file 12: Figure S6. PBRM1 expression in CcCRCC and TCGA cohorts. a PBRM1 expression represented by log 10 RSEM values are compared between missense mutation, truncating mutation and wild type in the TCGA cohort. Kruskal-Wallis test was performed across mutation type. b PBRM1 expression represented by log 10 RSEM values are compared between tumor and normal samples in CccRCC cohort. Wilcoxon test was performed between tumor and normal

\section{Acknowledgements}

We acknowledge Mr. Shijun Yu from Crown Bioscience for logistic assistance of the study. We thank two anonymous reviewers for providing helpful comments on earlier drafts of the manuscript.

\section{Authors' contributions}

Conceptualization: NZ and SG. Data curation: QZ, JX, BH, WQ, YJ, JL and TL. Formal analysis: QZ, JX, BH and BF. Funding acquisition: NZ and BH. Methodology: JC, QL and SG. Project administration and supervision: YY and QL. Original draft writing: JX and BH. All authors read and approved the final manuscript.

\section{Funding}

This study was supported by the National Natural Science Foundation of China (grant No. 81372738); Capital's Funds for Health Improvement and Research (grant No. 2020-2-1024); Science Foundation of Peking University Cancer Hospital (grant No. 2020-20).

\section{Availability of data and materials}

The Chinese ccRCC RNA-Seq dataset for this study is available at Gene Expression Omnibus (GEO) with accession number: GSE126964. The R scripts used for transcriptomic data analysis is available at Github repository: https://githu b.com/lindashirley99/CccRCC.

\section{Ethics approval and consent to participate}

Written informed consent was obtained for all samples from all participants at the time when samples were collected. This research was approved by the Institutional Review Board of Peking University Cancer Hospital \& Institute and is in accordance with the Declaration of Helsinki.

\section{Consent for publication}

Written consent for publication was obtained from all patients involved.

\section{Competing interests}

Authors Jia Xue, Wubin Qian, Bin Fan, Jie Cai, Qixiang Li and Sheng Guo were employed by the company Crown Bioscience. The remaining authors declare that the research was conducted in the absence of any commercial or financial relationships that could be construed as a potential conflict of interest.

\section{Author details}

${ }^{1}$ Key laboratory of Carcinogenesis and Translational Research (Ministry of Education/Beijing), Department of Urology, Peking University Cancer Hospital \& Institute, 52 Fucheng Road, Haidian District, Beijing 100142, People's Republic of China. ${ }^{2}$ Systems Biology, Crown Bioscience Inc., No. 218 Xinghu Street, Suzhou Industrial Park, Suzhou 215028, People's Republic of China. ${ }^{3}$ Department of Urology, Daqing Oilfield General Hospital, Heilongjiang 163316, People's Republic of China. ${ }^{4}$ Crown Bioscience Inc., No.21 Huoju Street Changping District, Beijing 102200, People's Republic of China.

${ }^{5}$ Crown Bioscience Inc., 3375 Scott Blvd, Suite 108, Santa Clara, CA 95054, USA.

${ }^{6}$ State Key Laboratory of Natural and Biomimetic Drugs, Peking University, Beijing 100191, People's Republic of China.

Received: 14 July 2020 Accepted: 10 September 2020

Published online: 22 September 2020

\section{References}

1. Siegel RL, Miller KD, Jemal A. Cancer statistics, 2015. CA Cancer J Clin. 2015;65(1):5-29.

2. Lane BR, Kattan MW. Prognostic models and algorithms in renal cell carcinoma. Urol Clin North Am. 2008; 35(4):613-625; vii.

3. Phillips CK, Taneja SS. The role of lymphadenectomy in the surgical management of renal cell carcinoma. Urol Oncol. 2004;22(3):214-23 (discussion 223-214)

4. Crispen PL, Breau RH, Allmer C, Lohse CM, Cheville JC, Leibovich BC, Blute ML. Lymph node dissection at the time of radical nephrectomy for highrisk clear cell renal cell carcinoma: indications and recommendations for surgical templates. Eur Urol. 2011;59(1):18-23.

5. Haddad H, Rini Bl. Current treatment considerations in metastatic renal cell carcinoma. Curr Treat Options Oncol. 2012;13(2):212-29.

6. Linehan WM. Genetic basis of kidney cancer: role of genomics for the development of disease-based therapeutics. Genome Res. 2012;22(11):2089-100.

7. Brannon AR, Reddy A, Seiler M, Arreola A, Moore DT, Pruthi RS, Wallen EM, Nielsen ME, Liu H, Nathanson KL, et al. Molecular stratification of clear cell renal cell carcinoma by consensus clustering reveals distinct subtypes and survival patterns. Genes Cancer. 2010;1(2):152-63.

8. Cancer Genome Atlas Research N. Comprehensive molecular characterization of clear cell renal cell carcinoma. Nature. 2013;499(7456):43-9.

9. Senbabaoglu Y, Gejman RS, Winer AG, Liu M, Van Allen EM, de Velasco G, Miao D, Ostrovnaya I, Drill E, Luna A, et al. Tumor immune microenvironment characterization in clear cell renal cell carcinoma identifies prognostic and immunotherapeutically relevant messenger RNA signatures. Genome Biol. 2016;17(1):231.

10. Davis CF, Ricketts CJ, Wang M, Yang L, Cherniack AD, Shen H, Buhay C, Kang H, Kim SC, Fahey CC, et al. The somatic genomic landscape of chromophobe renal cell carcinoma. Cancer Cell. 2014;26(3):319-30.

11. Cancer Genome Atlas Research N, Linehan WM, Spellman PT, Ricketts CJ, Creighton CJ, Fei SS, Davis C, Wheeler DA, Murray BA, Schmidt L, et al. Comprehensive molecular characterization of papillary renal-cell carcinoma. N Engl J Med. 2016;374(2):135-45.

12. Carlo MI, Chaim J, Patil S, Kemel Y, Schram AM, Woo K, Coskey D, Nanjangud GJ, Voss MH, Feldman DR, et al. Genomic characterization of renal medullary carcinoma and treatment outcomes. Clin Genitourin Cancer. 2017;15(6):e987-94

13. Chen F, Zhang Y, Senbabaoglu Y, Ciriello G, Yang L, Reznik E, Shuch B, Micevic G, De Velasco G, Shinbrot E, et al. Multilevel genomics-based taxonomy of renal cell carcinoma. Cell Rep. 2016;14(10):2476-89.

14. Rebbeck TR. Prostate cancer disparities by race and ethnicity: from nucleotide to neighborhood. Cold Spring Harb Perspect Med. 2017;8:a030387.

15. Nomura SJO, Hwang YT, Gomez SL, Fung TT, Yeh SL, Dash C, Allen L, Philips S, Hilakivi-Clarke L, Zheng YL, et al. Dietary intake of soy and cruciferous vegetables and treatment-related symptoms in Chinese-American and non-Hispanic White breast cancer survivors. Breast Cancer Res Treat. 2017;168:467-79.

16. Shi Y, Steppi A, Cao Y, Wang J, He MM, Li L, Zhang J. Integrative comparison of mRNA expression patterns in breast cancers from Caucasian and Asian Americans with implications for precision medicine. Cancer Res. 2017;77(2):423-33. 
17. Chevrier S, Levine JH, Zanotelli VRT, Silina K, Schulz D, Bacac M, Ries CH, Ailles $\mathrm{L}$, Jewett MAS, Moch $\mathrm{H}$, et al. An immune atlas of clear cell renal cell carcinoma. Cell. 2017:169(4):736-749.e718.

18. Lavin Y, Kobayashi S, Leader A, Amir ED, Elefant N, Bigenwald C, Remark $\mathrm{R}$, Sweeney R, Becker CD, Levine JH, et al. Innate immune landscape in early lung adenocarcinoma by paired single-cell analyses. Cell. 2017;169(4):750-765.e717.

19. Qian M, Wang DC, Chen H, Cheng Y. Detection of single cell heterogeneity in cancer. Semin Cell Dev Biol. 2017:64:143-9.

20. Zheng C, Zheng L, Yoo JK, Guo H, Zhang Y, Guo X, Kang B, Hu R, Huang JY, Zhang $Q$, et al. Landscape of infiltrating $T$ cells in liver cancer revealed by single-cell sequencing. Cell. 2017;169(7):1342-1356.e1316.

21. Wang K, Singh D, Zeng Z, Coleman SJ, Huang Y, Savich GL, He X, Mieczkowski P, Grimm SA, Perou CM, et al. MapSplice: accurate mapping of RNA-seq reads for splice junction discovery. Nucleic Acids Res. 2010;38(18):e178.

22. Li B, Dewey CN. RSEM: accurate transcript quantification from RNA-Seq data with or without a reference genome. BMC Bioinform. 2011:12:323.

23. Dobin A, Davis CA, Schlesinger F, Drenkow J, Zaleski C, Jha S, Batut P, Chaisson M, Gingeras TR. STAR: ultrafast universal RNA-seq aligner. Bioinformatics. 2013;29(1):15-21.

24. McKenna A, Hanna M, Banks E, Sivachenko A, Cibulskis K, Kernytsky A, Garimella K, Altshuler D, Gabriel S, Daly M, et al. The Genome Analysis Toolkit: a MapReduce framework for analyzing next-generation DNA sequencing data. Genome Res. 2010;20(9):1297-303.

25. Genomes Project C, Abecasis GR, Altshuler D, Auton A, Brooks LD, Durbin RM, Gibbs RA, Hurles ME, McVean GA. A map of human genome variation from population-scale sequencing. Nature. 2010;467(7319):1061-73.

26. Fu W, O'Connor TD, Jun G, Kang HM, Abecasis G, Leal SM, Gabriel S, Rieder MJ, Altshuler D, Shendure J, et al. Analysis of 6,515 exomes reveals the recent origin of most human protein-coding variants. Nature. 2013:493(7431):216-20

27. Forbes SA, Beare D, Gunasekaran P, Leung K, Bindal N, Boutselakis H, Ding M, Bamford S, Cole C, Ward S, et al. COSMIC: exploring the world's knowledge of somatic mutations in human cancer. Nucleic Acids Res. 2015;43(Database issue):D805-11.

28. Jia W, Qiu K, He M, Song P, Zhou Q, Zhou F, Yu Y, Zhu D, Nickerson ML, Wan $\mathrm{S}$, et al. SOAPfuse: an algorithm for identifying fusion transcripts from paired-end RNA-Seq data. Genome Biol. 2013;14(2):R12.

29. Nicorici D, Satalan M, Edgren H, Kangaspeska S, Murumagi A, Kallioniem O, Virtanen S, Kilkku O. FusionCatcher-a tool for finding somatic fusion genes in paired-end RNA-sequencing data. bioRxiv; 2014.

30. Krzywinski M, Schein J, Birol I, Connors J, Gascoyne R, Horsman D, Jones SJ, Marra MA. Circos: an information aesthetic for comparative genomics. Genome Res. 2009;19(9):1639-45.

31. Turro E, Su SY, Goncalves A, Coin LJ, Richardson S, Lewin A. Haplotype and isoform specific expression estimation using multi-mapping RNA-seq reads. Genome Biol. 2011;12(2):R13.

32. Leek JT JW, Parker HS, Fertig EJ, Jaffe AE, Storey JD, Zhang Y, Torres LC. sva: surrogate variable analysis. In., R package version 3.26 .0 edn; 2017.

33. Krijthe JH. T-Distributed Stochastic Neighbor Embedding using BarnesHut implementation. In., R package version 0.13 edn; 2015.

34. Ritchie ME, Phipson B, Wu D, Hu Y, Law CW, Shi W, Smyth GK. limma powers differential expression analyses for RNA-sequencing and microarray studies. Nucleic Acids Res. 2015;43(7):e47.

35. Hanzelmann S, Castelo R, Guinney J. GSVA: gene set variation analysis for microarray and RNA-seq data. BMC Bioinform. 2013;14:7.

36. Liberzon A, Subramanian A, Pinchback R, Thorvaldsdóttir H, Tamayo $P$, Mesirov JP. Molecular signatures database (MSigDB) 3.0. Bioinformatics. 2011:27(12):1739-40.

37. Gaujoux R, Seoighe C. A flexible R package for nonnegative matrix factorization. BMC Bioinform. 2010;11:367.

38. Chen EY, Tan CM, Kou Y, Duan Q, Wang Z, Meirelles GV, Clark NR, Ma'ayan A. Enrichr: interactive and collaborative HTML5 gene list enrichment analysis tool. BMC Bioinform. 2013;14:128.

39. Kuleshov MV, Jones MR, Rouillard AD, Fernandez NF, Duan Q, Wang Z, Koplev S, Jenkins SL, Jagodnik KM, Lachmann A, et al. Enrichr: a comprehensive gene set enrichment analysis web server 2016 update. Nucleic Acids Res. 2016;44(W1):W90-7.

40. Cancer Genome Atlas Research Network. Electronic address wbe, Cancer Genome Atlas Research N. Comprehensive and Integrative Genomic Characterization of Hepatocellular Carcinoma. Cell. 2017;169(7):13271341.e1323.

41. Racle J, de Jonge K, Baumgaertner P, Speiser DE, Gfeller D. Simultaneous enumeration of cancer and immune cell types from bulk tumor gene expression data. Elife. 2017;6:e26476.

42. Kandoth C, McLellan MD, Vandin F, Ye K, Niu B, Lu C, Xie M, Zhang Q, McMichael JF, Wyczalkowski MA, et al. Mutational landscape and significance across 12 major cancer types. Nature. 2013;502(7471):333-9.

43. Goodman AM, Kato S, Bazhenova L, Patel SP, Frampton GM, Miller V, Stephens PJ, Daniels GA, Kurzrock R. Tumor mutational burden as an independent predictor of response to immunotherapy in diverse cancers. Mol Cancer Ther. 2017;16(11):2598-608.

44. Samstein RM, Lee CH, Shoushtari AN, Hellmann MD, Shen R, Janjigian YY, Barron DA, Zehir A, Jordan EJ, Omuro A, et al. Tumor mutational load predicts survival after immunotherapy across multiple cancer types. Nat Genet. 2019;51(2):202-6.

45. Kung CP, Maggi LB Jr, Weber JD. The role of RNA editing in cancer development and metabolic disorders. Front Endocrinol (Lausanne). 2018;9:762.

46. Joseph RW, Kapur P, Serie DJ, Parasramka M, Ho TH, Cheville JC, Frenkel E, Parker AS, Brugarolas J. clear cell renal cell carcinoma subtypes identified by BAP1 and PBRM1 expression. J Urol. 2016;195(1):180-7.

47. Kluzek K, Srebniak MI, Majer W, Ida A, Milecki T, Huminska K, van der Helm RM, Silesian A, Wrzesinski TM, Wojciechowicz J, et al. Genetic characterization of Polish ccRCC patients: somatic mutation analysis of PBRM1, BAP1 and KDMC5, genomic SNP array analysis in tumor biopsy and preliminary results of chromosome aberrations analysis in plasma cell free DNA. Oncotarget. 2017;8(17):28558-74.

48. Chowdhury B, Porter EG, Stewart JC, Ferreira CR, Schipma MJ, Dykhuizen EC. PBRM1 regulates the expression of genes involved in metabolism and cell adhesion in renal clear cell carcinoma. PLOS ONE. 2016;11(4):e0153718.

49. Miao D, Margolis CA, Gao W, Voss MH, Li W, Martini DJ, Norton C, Bosse D, Wankowicz SM, Cullen D, et al. Genomic correlates of response to immune checkpoint therapies in clear cell renal cell carcinoma. Science. 2018;359:801-6.

50. Rodriguez-Canales J, Parra-Cuentas E, Wistuba II. Diagnosis and molecular classification of lung cancer. Cancer Treat Res. 2016:170:25-46.

51. Ricketts CJ, De Cubas AA, Fan H, Smith CC, Lang M, Reznik E, Bowlby R, Gibb EA, Akbani R, Beroukhim R, et al. The Cancer Genome Atlas comprehensive molecular characterization of renal cell carcinoma. Cell Rep. 2018;23(1):313-326.e315

52. Newman $A M$, Liu CL, Green MR, Gentles AJ, Feng W, Xu Y, Hoang CD, Diehn M, Alizadeh AA. Robust enumeration of cell subsets from tissue expression profiles. Nat Methods. 2015;12(5):453-7.

53. LiT, Fan J, Wang B, Traugh N, Chen Q, Liu JS, Li B, Liu XS. TIMER: a web server for comprehensive analysis of tumor-infiltrating immune cells. Cancer Res. 2017;77(21):e108-10.

54. Chen SH, Kuo WY, Su SY, Chung WC, Ho JM, Lu HH, Lin CY. A gene profiling deconvolution approach to estimating immune cell composition from complex tissues. BMC Bioinform. 2018;19(Suppl 4):154.

55. Thorsson V, Gibbs DL, Brown SD, Wolf D, Bortone DS, Ou Yang TH, PortaPardo E, Gao GF, Plaisier CL, Eddy JA, et al. The Immune Landscape of Cancer. Immunity. 2018;48(4):812-830.e814.

\section{Publisher's Note}

Springer Nature remains neutral with regard to jurisdictional claims in published maps and institutional affiliations. 